\title{
Collaborating with an instructional designer to develop a quality learner-engaged online course
}

\author{
Debra L. Wagner ${ }^{* 1}$, Kevin G. Hulen ${ }^{2}$ \\ ${ }^{1}$ School of Nursing, Brooks College of Health, University of North Florida, Jacksonville, United States \\ ${ }^{2}$ Center for Instruction and Research Technology, University of North Florida, Jacksonville, United States
}

Received: June 23, 2015

DOI: $10.5430 /$ jnep.v6n4p40
Accepted: December 9, $2015 \quad$ Online Published: December 13, 2015

URL: http://dx.doi.org/10.5430/jnep.v6n4p40

\begin{abstract}
As increasing numbers of registered nurses pursue a Bachelor of Science in Nursing degree, many choose online programs to reach their goal, prompting nursing faculty to convert traditional face-to-face courses to an online format. Providing an excellent learning experience may prove challenging for faculty unfamiliar with the technology needed to construct a quality learner-engaged online course. While nursing faculty provide expertise in the subject matter, an instructional designer assists in streamlining the design and development of the course, supplying fresh ideas to engage students using current teaching pedagogy and technology tools. This paper describes the benefits of collaborating with an instructional designer to produce a quality course and how working with an instructional designer can increase faculty technology skills and knowledge of new teaching methodologies while also improving the learner's engagement in an online course through a quality educational experience.
\end{abstract}

Key Words: Instructional design, Learner engagement, Online course

\section{INTRODUCTION}

The Institute of Medicine (IOM) recommended $80 \%$ of nurses hold at least a baccalaureate degree in nursing by the year 2020, as the challenges of caring for an aging and increasingly medically complex population continue to grow. ${ }^{[1]}$ As a result, registered nurses who earned their licensure through associate degree or diploma programs are encouraged to return to school for a Bachelor of Science in Nursing (BSN) degree. This creates both a challenge and an opportunity for colleges and universities to provide programs allowing more nurses to return to school to complete their baccalaureate education.

Nurses cite family and work obligations, financial considerations, and lack of time as some of the reasons for not pursuing higher education. ${ }^{[2]}$ They relate the need for flexibility and convenience in order to maintain their work schedule and other obligations. Some need portability in the event of relocation, such as those affiliated with the military, ${ }^{[3]}$ and the ability to take classes online gives them some flexibility and control over how and when they engage in the course. ${ }^{[4]}$ Thus, the number of online RN-BSN programs across the country has greatly increased, as evident by the advertisements in nursing publications, television commercials, online pop-ups, and social media postings. This presents formidable challenges for faculty that, in addition to ensuring their students receive a quality educational experience in their courses, also need to stay up-to-date on the latest technology and best practices for online delivery.

As the demand for quality online courses continues to increase, the response by many institutions of higher education

*Correspondence: Debra L. Wagner; Email: dwagner@unf.edu; Address: School of Nursing, University of North Florida, 1 UNF Drive, Jacksonville, Florida, United States. 
has been to seek national standards in course design and format to guide the online course development process. No longer is it acceptable for an instructor to simply "dump" their traditional-based classroom content into the online environment. At many institutions, the process of developing online courses is a collaborative effort that joins the content expertise of the instructor with the educational and technological expertise of an instructional designer. In this collaboration, the instructor serves as the content expert, bringing knowledge of the subject matter, while the instructional designer contributes knowledge of course design, educational and technological best practices, and expertise in adult and distance education to the course development process. ${ }^{[5]}$

Instructional designers bring a wealth of experience to the process of course design. Many have extensive teaching experience, have taught at the collegiate level, have knowledge of educational technologies, and are experts in the functionality and vulnerabilities of the Learning Management System (LMS). They are familiar with the rigor of academia and have the skills to design content specifically for the online format. Their expertise lies in envisioning the learning components of a course and translating them into a quality educational experience. ${ }^{[6]}$ Through instructional design principles and best practices as proposed by instructional designers, courses become rewarding, offer diverse learning opportunities and deliver an excellent educational experience for the students. ${ }^{[7]}$

In this paper we describe how the collaboration between an instructor and instructional designer can bring about a quality learner-engaged online course, one that can greatly enhance the students' ability to acquire the expected knowledge while maintaining engagement within an online course. In addition, we outline definitive strategies used in the design and development of all courses within a fully online RN-BSN program at a university in northeast Florida.

\section{THE PARTNERSHIP}

Transitioning a traditional face-to-face course to fully online presents challenges for faculty, especially those who have not previously taught online. While they may be experts in the content area and know exactly what students should achieve by the end of the course, they may not be familiar with common pedagogical, logistical, and technological strategies used to design and deliver effective online courses. In particular, some of the more common tools for delivering online content, such as, podcasts, video lectures, narrated PowerPoints, discussion boards, blogs, wikis, and journals, ${ }^{[3,4,8-10]}$ may not be familiar to most nursing faculty. By partnering with an instructional designer who is cognizant of best online practices and familiar with the strengths and weaknesses of the LMS in which the online courses are deployed, faculty can put more effort towards curriculum planning to ensure that students meet the desired educational outcomes ${ }^{[6]}$ and less effort towards uploading and formatting content inside the LMS.

The best way to establish this collaborative partnership is for the online instructor to begin by meeting with the instructional designer in person, preferably several months before the course goes "live". During these initial meetings, the instructor and instructional designer should discuss courselevel outcomes and identify measurable learning objectives that align with specific assignments and other critical course requirements. Quality online courses reflect assessments that align with objectives, and use up-to-date strategies and activities to help students interact with the content. ${ }^{[11]}$ Effective learning takes place when students sense a feeling of community in the beginning of a course and experience assorted ways to interact with each other and the faculty while learning the subject material. ${ }^{[12]}$ Once the overall purpose and goals for the course have been outlined and the online instructor is comfortable with the partnership, the next step is to discuss common pedagogical, logistical, and technological strategies for developing the online course.

\section{Course development}

Through the instructional designers' lens, the development of an online course is like putting together a puzzle with an "undetermined number of pieces" that must all join together before the "actual pattern" is revealed. The "undetermined number of pieces" include all elements of the online course that need to be defined and implemented before the course can be effectively delivered and the "actual pattern" is the eventual final online course. While this clearly presents a number of challenges for instructional designers, it is also familiar territory for them. The primary goal for the instructional designer is not only to develop a course that is comparable or better than the original face-to-face version of the course, but to develop a quality learner-engaged online course, one that may involve the creation of new elements that did not exist in the traditional face-to-face version of the course.

\subsection{Course template}

To ensure all courses within the fully online RN-BSN program presented a quality learner-engaged experience for students-one where students did not experience unnecessary frustrations-a course template was developed and applied to each course in the program (see Figure 1). A course template exhibits best practices in course navigation, accessibility, technology, and effectively organizes the course content, all 
of which promote a more effective learning experience for students. This uniformity enables students to intuitively navigate the course, easily find assignments and resources in each module, and provides multiple modalities for them to engage with their peers. In addition, applying the template to all courses within the program provides students the benefit of "knowing" where to find similar resources as they progress through the online program. In contrast to some speculation and skepticism by faculty, applying the same strategic design for all online courses in a particular program does not stifle academic freedom; rather it serves to lessen the amount of time or frustration faculty experience building their courses and students experience trying to navigate through them.

The course template, which has been used institutionally to develop over 100 online courses and four fully online degree programs, incorporates the following core best practices (in addition to many other not listed):

- Consistent layout and simple navigation, which requires a simple course menu (see Figure 1a).

- Home page with course banner, links to syllabus and course schedule, instructor contact information, and textbooks (see Figure 1b).

- Start Here page with information on assignments, communication, grading policies. Also, contains a Student Orientation quiz that students must pass with a $100 \%$ score before they can access the Learning Modules (see Figure 1c).

- Learning Modules with five primary sections: Module Banner, Purpose Statement, Learning Objectives, Agenda, and Assignments. All assignments contain instructions and grading rubrics (see Figure 1d).

- Standard discussion forums for "Technical Issue" and "Questions about course content" in addition to module specific forums.

- Help page with course and institutional policies, and statements about technology use, accessibility, distance learning services, and other learner support services.

- Built-in accessibility and elements of Universal Design for Learning (UDL), such as, standard font-types, font-sizes, font-colors, and link styles applied throughout the course to facilitate readability and minimize distractions.

\subsection{Course schedule}

A well-designed course schedule is an essential component of a quality online course. The course schedule should above all else make it clear to students when assignments are due so they can plan their study schedule for the week, or even the entirety of the academic term. This is in line with giving students the flexibility to work on course material around the time available in their personal schedules. Moreover, providing clearly identified times for students to turn in assignments helps them properly pace themselves throughout the course. All courses within the online RN-BSN program used the same course schedule layout to present the course assignments and due dates (see Figure 2).

Perhaps the most challenging aspect of implementing a standard course schedule across all courses in the online program was justifying the simplistic layout. Many instructors had been using course schedule that contained far more information than was allowed in the program-based design. The logic behind using a more concise course schedule is all "other" information (readings, assignments notes, chapter exercises) already exists in the course modules, and in a more detailed format. Replicating the same information in multiple places was not considered a best practice as it increases the amount of materials/instructions students must read and multiplies the number of areas within the course instructors must modify as the course evolves semester-to-semester. In positioning specific course materials at decisive locations within the course, redundancy decreased, course design streamlined, and the integrity of the course template was retained, all of which enhanced the quality of development and delivery of all courses within the RN-BSN program.

\subsection{Communication}

Instructor-student communication in the online course was initiated primarily through three distinct tools within the LMS (Email, Announcements, and Discussions), all of which were decisive in meeting the primary objective of scaffolding the learning environment through clear expectations.

The "Email" tool was only used to send emails to individual students. Messages that needed to reach larger groups of students were sent using the "Announcement" tool or posted using the "Discussion Board" tool. Instructions on the proper way to send and respond to emails and post to discussion boards (called Netiquette) were included in the "Start Here" section of the course (see Figure 1b). The Netiquette section included the following do's and don'ts about communicating in online courses:

- Do...

- Ask questions and engage in conversations as often as possible-feel free to contact the instructor via the discussion forum for questions or via email or other communication.

- Be patient and respectful of others and their ideas and opinions they post online.

- Be prepared for some delays in response time, as 
"virtual" communication tends to be slower than "face-to-face" communication.

- Check the syllabus and course policies stated by your instructor to know what to expect about - Don't... your instructor's turnaround time for responding.

- Use inappropriate language-this includes, but is not limited to, the use of curse words, swearing, or terms that imply inappropriate things.

- Post inappropriate materials-for example, acci- dentally posting/showing a picture of a nude person or something to that affect would result in great consequences.

- Post in ALL CAPS, as this is perceived as shouting and avoid abbreviations and informal language ("I'll C U L8R").

- Send heated messages even if you are provoked. Likewise, if you should happen to receive a heated message, do not respond to it. a

\begin{tabular}{|l|}
\hline HOME \\
START HERE \\
ANNOUNCEMENTS \\
LEARNING MODULES \\
DISCUSSIONS \\
GRADES \\
MAIL \\
TOOLS \\
HELP \\
\hline
\end{tabular}

b

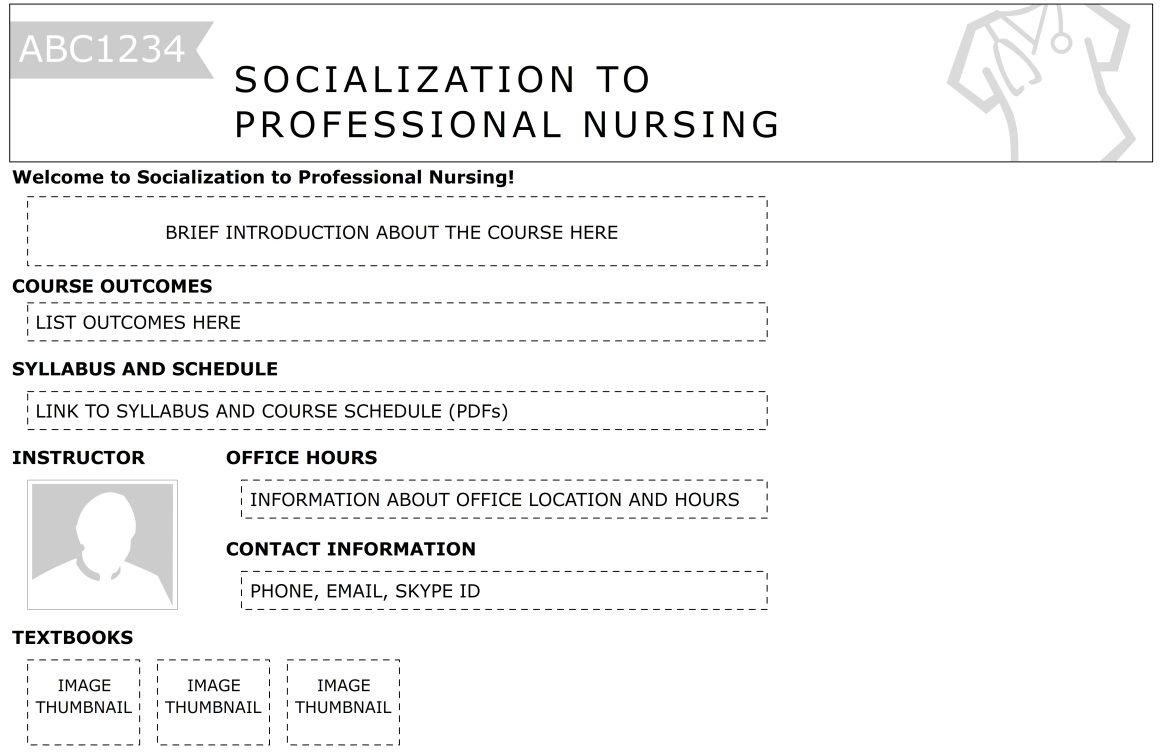

C

START H E R E
COURSE OVERVIEW
INFORMATION ABOUT THE COURSE GOES HERE
LEARNING MODULES
INFORMATION ABOUT THE STRUCTURE OF THE MODULES
ASSIGNMENTS
BRIEF OVERVIEW ABOUT THE DIFFERENT TYPES OF ASSIGNMENTS
GRADES AND FEEDBACK
WHEN CAN STUDENT EXPECT TO GET FEEDBACK ON ASSIGNMENTS?
COURSE EXPECTATIONS
TO BE SUCCESSFUL IN THIS COURSE, STUDENTS SHOULD?
COMMUNICATION
COMMUNICATION IN THIS COURSE WILL OCCUR AS FOLLOWS:
NETIQUETTE
DO'S AND DON'T OF ONLINE COMMUNICATION
QUIZ: STUDENT ORIENTATION
BLOG: INTRODUCE YOURSELF

MODULE 1

\begin{tabular}{l} 
PURPOSE \\
\hline STATEMENT ABOUT THE PURPOSE OF THIS MODULE \\
LEARNING OUTCOMES \\
\hline STATEMENTS ABOUT WHAT STUDENTS WILL BE ABLE TO DO \\
AGENDA \\
RIEW \\
PIST OF ASSIGNED READINGS \\
WATCH \\
LINKS TO ONLINE VIDEOS \\
ASSIGNMENTS \\
\hline LIST OF ASSIGNMENTS TO BE COMPLETED IN THIS MODULE \\
\hline DISCUSSION BOARD (post/reply) \\
\hline - MODULE QUIZ \\
\hline
\end{tabular}

Figure 1. Schematic layout of the course template used to develop all ten courses in the fully online RN-BSN program. (a) Course Menu, (b) Home page, (c) Start Here page, and (d) Module layout

Dashed boxes indicate where course-specific or module-specific information was inserted. 


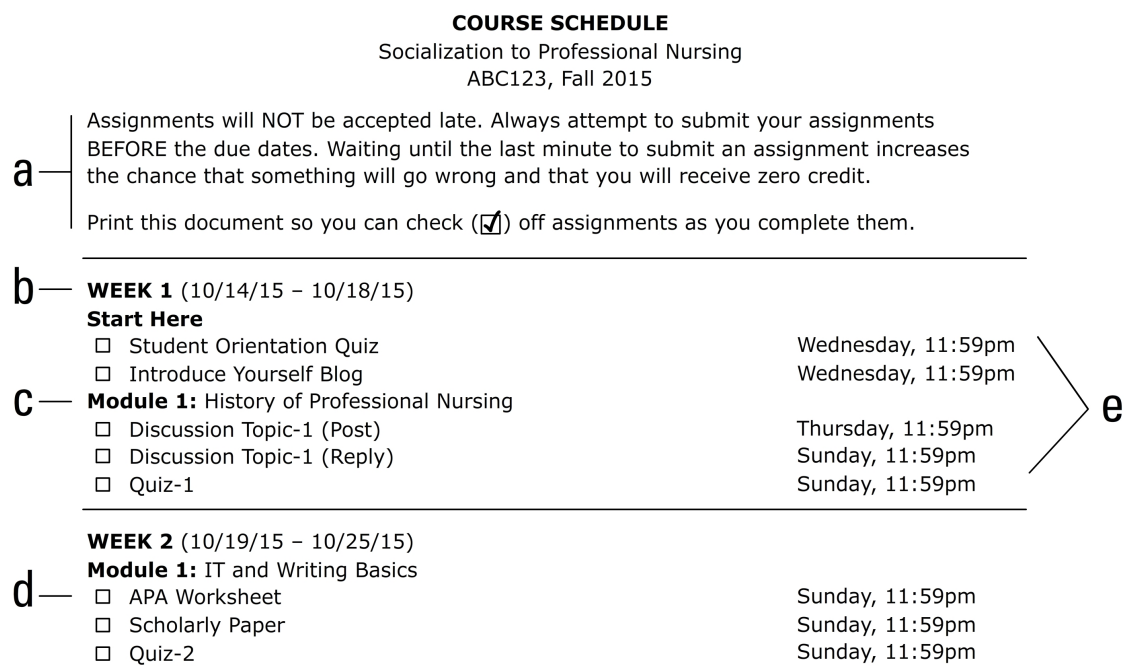

Figure 2. Schematic layout of the course schedule used in all courses within the online RN-BSN program: (a) General instructions on how to use the schedule, (b) Week number $(1,2,3)$ with start and end dates for the given week, (c) Module number $(1,2,3)$ with module title, (d) Assignment name exactly as it is listed in the LMS, and (e) Assignment due date, which is applied to the assignment in the LMS

Informative and well-structured announcements were sent at the beginning of each week. First time online instructors often make the mistake of using the "Announcement" tool to distribute everything they want to say, which essentially overloads the communication channel. As a result, students often overlook those announcements, which in turn leads instructors to think, "I send tons of announcements, why don't my students read them?" The overuse of announcements in an online course is usually an indication of insufficient scaffolding throughout the learning environment. As a best practice, announcements were sent at the beginning of each week and followed a consistent format as follows:

- A "welcome to the week/module" statement.

- Something in the news related to week's content.

- A brief list of things students should pay attention to that week, or assignments they should complete by the end of the week.

- Some things student should start reviewing in advance of the following week. This encourages students be more proactive.

\subsection{Learning modules and assignments}

A chunking strategy presented course materials in a logical and progressive order. The concept of chunking works by presenting large amounts of content in small modules to make the information meaningful and easier to understand. ${ }^{[13]}$ Within each module, information was chunked further into four sections: Purpose, Learning Objectives,
Agenda, and Assignments. Alignment between learning objectives and assignments was essential so that students saw the practicality and relevancy of the activity instead of feeling they are doing "busy work". Each module was formatted to present the course materials in a clear manner easily understood by the students, as validated by student comments of "there is more than enough information provided to give us a clear understanding of what is expected of us"; "the course is very detailed and well prepared; there is nothing more I feel needs to be elaborated any further", and "I feel that the course is very well presented; the assignments are very well explained and relevant."

Providing a diversity of assignments, both asynchronous and synchronous, encourages students to interact with classmates, rather than just reading a textbook or watching/listening to recorded lectures. Active engagement and interaction in the learning process is important, as students feel these types of assignments are more personalized and project a sense of faculty caring. ${ }^{[3]}$ Interacting through asynchronous assignments such as discussion boards and Wikis, or through synchronous assignments using real-time communication and collaboration software, allows students to build a sense of community with their peers, which enhances the learning experience for all students. The inclusion of synchronous assignments, such as group presentations, provide an advantage to the students and instructors in the online environment by being able to engage instantly and at the same point in time, which lends a feeling of meeting and interacting in a more personal way. 
Instructional designers are most knowledgeable in determining which tools (asynchronous vs. synchronous) would bring about the best synergy and engagement among all members in the online environment. Once the appropriate tool is chosen, the instructional designer strategically builds the assignment inside the LMS, which includes carefully articulated instructions, assignment expectations, grading criteria, and rules for uploading the assignment into the LMS.

\subsection{Discussions}

Discussions are an essential component of effective online courses because they facilitate many different types of interactions, such as instructor-student, student-student, and student-content. Two discussion forums were setup using the "Discussion Board" tool where students could post questions about course content or technical issues. In those particular forums, other students could jump in and answer their peers' questions, creating a sense of community and helpfulness. The primary role of the online instructor was to moderate the forums and to answer questions regarding content or assignments as necessary. While the design of these forums was to promote student-student communication, they also served well in providing the online instructor with a means to post and respond to frequently asked questions (FAQ's). By posting FAQ's in the discussion forum the instructor could avoid making the mistake of "overloading" the announcements area while still being able to communicate with the entire class as a whole. Students appreciate these resources as evidenced by statements on the midterm survey such as "there are a lot of really awesome resources made available to us through this course".

\section{GRADES AND STUDENT FEEDBACK}

Evaluation of student learning is always a major focus of discussion during the course development process, and providing students with clear and concise grading rubrics for all assignments should be one of the primary goals from such discussions. A well-constructed rubric provides evaluation criteria that are detailed and specific. ${ }^{[13]}$ Rubrics help students see how the grade is determined, thereby giving them additional direction in preparation of the assigned work. These rubrics help to ensure student accountability by clearly writing out the performance expectations with specific criteria before the assignment is submitted. ${ }^{[14,15]}$

Instructional designers can assist faculty with developing a useful and meaningful rubric as they have the background and experience in the construction of well-defined criteria. Whenever possible, grading rubrics should be built-in to the LMS to allow the faculty to add comments in each block of the rubric (see Figure 3). This feedback lets students know

Published by Sciedu Press exactly where and why points are subtracted so that they can improve future work. It also provides an area for faculty to provide useful feedback to students, which can serve to reinforce the learning goals and foster a positive learning community.

Unless faculty survey students about the online course, what do they really know? Put another way, can they honestly say their online course was successful without having acquired and analyzed any quantitative or qualitative feedback from the students? Students should be given opportunities to provide feedback on the course and assignments to their instructors. Anonymous student surveys serve this purpose very effectively.

Instructional designers can help construct a survey that can be deployed in the midpoint of the course, so faculty can see if there are areas in the instructions or layout of the course that need improvement. These surveys identify areas whereby the instructional designer or faculty can make adjustments to future offerings of the course. Further, this allows students a forum to give feedback regarding the format of the course, or suggest ways to improve directions for assignments or clarify other areas of ambiguity within the course. By putting the survey in the middle of the course faculty can make appropriate changes right away instead of waiting until the course is over. It may be this practice will help decrease student's frustration and increase their satisfaction in taking the course.

\section{EXEMPLAR}

In one of the courses within the RN-BSN online program, a course objective for students was to discuss the health care system in which professional nursing exists. The dilemma for this online course was to figure out how to meet the objective in an engaging way other than a discussion board, since the students participated in a discussion board assignment in an earlier module in the course. The instructor and instructional designer consulted and decided that for this particular assignment students would meet this objective through the use of real-time communication and collaboration software. The software of choice was a virtual web based classroom provided by the university where students get to "talk" in real time via a built-in computer or headset microphone, or "text" via the chat board in the tool. This assignment was labeled, the "Collaborate" session.

To meet the course objective, students were provided with You Tube videos, journal articles, and websites within the learning module, where they could learn the various provisions of the Affordable Care Act (ACA), and were encouraged to explore any other materials they found in preparation for the Collaborate session. During the live session, students 
outlined the various aspects of the ACA-both pros and cons; the impact of ACA on their nursing practice; and the impact on the patients they care for.

The grading rubric was available before the session so the students could be prepared to earn the maximum number of points available for this assignment. They were graded based on the following criteria: 1) attendance in the session, 2) uploading a picture into their profile so that classmates (and faculty) could put a "face" to a "name", and 3) making at least one meaningful verbal contribution to the conversation (see Figure 3).

The "Wiki" tool built into the LMS was used as a means for students to signup for one of four sessions (two scheduled in the morning and two scheduled in the evening), based on their work time and personal availability. Sign-up space was limited in each session in order to allow each student at least one opportunity to speak during the Collaborate session.

The Collaborate session provided a great forum for the students to interact, especially those who were "shy" and might not speak up in the physical classroom, but felt comfortable doing it in the "virtual" classroom. The session gave all students in the class a chance to share with their classmates and colleagues some of the everyday issues they faced in the work place or in their personal lives (or those of friends and family) as a result of the ACA.

\begin{tabular}{|c|c|c|c|}
\hline \multirow[b]{2}{*}{ Criteria } & \multicolumn{3}{|l|}{ Levels of Achievement } \\
\hline & Not Met & Somewhat Met & Met \\
\hline Attendance & $\begin{array}{l}\text { O Points } \\
\text { Did not attend a session. }\end{array}$ & $\begin{array}{l}2 \text { Points } \\
\text { Attended the session but } \\
\text { not sign up beforehand. }\end{array}$ & $\begin{array}{l}3 \text { Points } \\
\text { Signed up on the Wiki } \\
\text { and attended the session. }\end{array}$ \\
\hline Picture & $\begin{array}{l}\text { O Points } \\
\text { No picture uploaded } \\
\text { into the session. }\end{array}$ & $\begin{array}{l}\text { O Points } \\
\text { No picture uploaded } \\
\text { into the session. }\end{array}$ & $\begin{array}{l}2 \text { Points } \\
\text { Picture of self uploaded } \\
\text { into the session. }\end{array}$ \\
\hline Participation & $\begin{array}{l}\text { O Points } \\
\text { Did not speak or text } \\
\text { on the chat board. }\end{array}$ & $\begin{array}{l}3 \text { Points } \\
\text { Provided comments to interact in } \\
\text { the session, but did not add verbal } \\
\text { contributions to the session. }\end{array}$ & $\begin{array}{l}5 \text { Points } \\
\text { Provided at least one } \\
\text { meaningful verbal } \\
\text { contribution to the session. }\end{array}$ \\
\hline
\end{tabular}

Figure 3. Grading rubric used to evaluate student participation in the Socialization to Professional Nursing course Collaborate session where students discussed the ACA

The sessions were limited to one hour, and faculty was careful to keep the session to the time limit, since many of these students worked 12 hours shifts and either just finished a work shift or had to work the next day. Faculty introduced the topic and gave some guidelines for the session, but since the controls on the program were set to give every student access to all tools, they were each able to act as moderators. As students warmed to the topic and got comfortable speaking to each other, the conversations became very lively and extremely interactive. Faculty commented as necessary to keep the conversation on topic and to further explore areas the students introduced, but primarily let the students share and learn from each other.

Following the Collaborate session the students' written evaluations were overwhelmingly positive. Comments on the midterm survey included "I loved the course, but offering more times and less students for the collaborative session would be nice; it was hard to get a word in"; "I enjoyed the Collaborate session and speaking to my peers concerning relevant issues in the nursing field"; and "I liked the Collab- orate session and hearing the views from fellow classmates. This was a good opportunity to meet the classmates given that this is a virtual class and I certainly see the value!"

\section{Conclusion}

As the demand for online courses and programs increase and the current nursing faculty ages, instructors may need to change the way they teach the curriculum to their students and learn new technology skills and pedagogy in order to accommodate a new population of online students in a relevant manner, while retaining credibility. Thus, instructional designers can serve as faculty mentors throughout the course development process. Working together in a partnership, with faculty as the subject matter expert and the instructional designer as the technical expert and advisor, a fresh approach to student learning can germinate. The result of this collaboration can produce a quality learner engaged online course.

\section{CONFlicts OF InTEREST Disclosure}

The authors declare that there is no conflict of interest. 


\section{REFERENCES}

[1] Institute of Medicine (IOM). The future of nursing: Leading change, advancing health. Washington DC: The National Academies Press; 2011.

[2] Sportsman S, Allen P. Transitioning associate degree in nursing students to the Bachelor of Science in Nursing and beyond: A mandate for academic partnerships. Journal of Professional Nursing. 2011; 27(96): e20-e27. PMid:22142922 http://dx.doi.org/10.1016 /j.profnurs.2011.08.004

[3] Mann JC. A pilot study of RN-BSN completion students' preferred instructor online classroom caring behaviors. The ABNF Journal. 2014; 25(2): 33-39. Available from: http://www. tuckerpub.co m/abnf .htm PMid:24855803

[4] Murray L, McCallum C, Petrosino C. Flipping the classroom experience: A comparison of online learning to traditional lecture. Journal of Physical Therapy Education. 2014; 28(3): 35-41. Available from: http://www . aptaeducaetion.org/members/jopte/

[5] Hixon E. Team-based online course development: A case study of collaboration models. 2008. Available from: http://www. westga . edu/ distance/ojdla/winter114/hixon114.html

[6] Ashbaugh ML. Expert instructional designer voices: Leadership competencies critical to global practice and quality online learning designs. The Quarterly Review of Distance Education. 2013; 14(2): 97-188.

[7] Carter L. Perceptions of writing confidence, critical thinking, and writing competence among registered nurses-learners studying online. Canadian Journal of University Continuing Education. 2008; 34(2): 63-85. Available from: http://ejournals.library.ualberta .ca/index.php/cjuce-rcepu/article/view/19960

[8] Conner NE, Thielemann PA. RN-BSN completion programs: Equipping nurses for the future. Nursing Outlook. 2013; 61: 458-
465. PMid:23618550 http://dx.doi.org/10.1016/j.outlook .2013 .03 .003

[9] Gyurko CC, Ullmann J. Using online technology to enhance educational mobility. Online Journal of Nursing Informatics (OJNI). 2012; 16(1). Available from: http://ojni.org/issues/?p=1270

[10] Hawks SJ. The flipped classroom: Now or never? AANA Journal. 2014; 82(4): 264-269. Available from: http: //www. aana.com/a anajournal/online PMid:25167605

[11] Salyers V, Carter L, Cairns S, et al. The use of scaffolding and interactive learning strategies in online courses for working nurses: Implications for adult and online education. Canadian Journal of University Education. 2014; 40(1): 1-17. Available from: https ://ej ournals.library.ualberta.ca/index.php/cjuce-rcepu

[12] Staffordshire University. Best practice models for elearning: Principles. 2013. Available from: https: //bestpracticemodels.wiki.staff.ac.us/Best_Pra ctice_Models-for-e-learning\%3a_Principles

[13] Miller GA. The magical number seven, plus or minus two: some limits on our capacity for processing information. Psychological Review. 1956; 63(2): 81-97. Available from: http://www.musanim.com/ miller1956/ PMid:13310704 http://dx.doi.org/10.1037/h 0043158

[14] Brown B, Eason SE, Jacobsen DM, et al. Instructional design collaboration: A professional learning and growth experience. Journal of Online Learning and Teaching. 2013, 9(3): 439-452. Available from: http://jolt.merlot.org/vol9no3/brown_0913.htm

[15] Naber JL, Theobold A. Development of a school of nursing rubric. Journal of Nursing Education and Practice. 2015; 5(9): 49-53. http://dx.doi.org/10.5430/jnep.v5n9p49 